\title{
新 年 寄 语
}

新年伊始, 首先向一直关心、支持、爱护《科学通报》的朋友们表示衷心的感谢, 并祝愿大家在新的一 年里工作顺利，身体健康!

过去一年中, 在广大科技工作者的热情支持和全体编委会、编辑部成员的共同努力下，《科学通报》顺 利完成了从半月刊向旬刊的过渡, 并取得了一定的进步和成绩. 编辑部将在 Chinese Science Bulletin 第一期向 读者简要地汇报 2010 年的工作(“A note from the editorial office”) ${ }^{[1]}$, 这里不再赘述. 下面谈谈我作为《科学通 报》主编，在这一年工作中的体会：

第一，广大科技工作者更加关心和支持中国科技期刊的发展.

科技工作者在各自研究领域取得重大成绩的同时，更加关心中国科技刊物的出版，更加愿意将自己的部 分主要成果发表在中国自己的刊物上, 并以此为自豪. 通过我们的约稿工作, 一些原来准备投到国外期刊的 稿件, 改投《科学通报》, 这让我们感到特别振奋. 有了这些优秀科学家的大力支持, 我们对办好《科学通报》 更加有信心, 干劲也更足了. 我们同时也希望广大科学家能一如既往关心支持《科学通报》, 把优秀稿件投到《科 学通报》，我们共同努力，使《科学通报》成为一个能全面系统反映我国科学成就的学术阵地和展示窗口.

第二, 很多热点研究领域集中涌现出一批优秀成果, 论文整体质量有明显提高.

2010 年, 《科学通报》论文的整体质量有所提高, 特别是在一些热点研究领域发表了相关专题. 专题文 章作者单位的分布面比以前宽了, 水平更是有了明显改善. 从这些稿件上可以折射出我国的科研发展趋势在 发生变化, 表现在：(1) 基础研究向更深的层次发展, 从原理上、机制上阐明问题的本质，而不再停留在对表 观的现象描述; (2) 更加关注国家的重大需求, 将基础研究与解决当前重大实际问题有机地结合起来, 如: 能 源、疾病、环境、自然灾害等与国计民生有关的重大问题; (3) 逐渐摆脱了跟随国际潮流的做法, 根据中国的 国情和自己实验室的基础, 走上一条独立自主发展的道路, 因而取得的成绩更受到国际的关注. 在这方面原 来基础较好的有地学, 现在物理学方面有高温超导、量子信息、等离子体光学等, 生命科学方面有与疾病有 关的基因、蛋白质研究等; (4) 我国的基础研究队伍开始成熟, 他们逐渐摆脱急功近利、浮躁不实的心理状态, 开始认真地考虑自己的长远目标, 踏下心来, 埋头苦干 10 年、 20 年, 向世界科学高峰冲击. 我国在主要基础 研究领域已经成长出一批新的研究基地和研究骨干, 反映了我国基础研究的基础更加扎实, 水平全面提高, 在世界上已经占有一席之地, 为攻克世界科学高峰创造了良好的条件.

总之, 优秀的科研成果是科技期刊发展的基础. 中国有句俗语: 巧妇难为无米之炊. 有米才能做出好饭 来. 中国的科学研究前途无限光明，《科学通报》的前景也无限光明. 让我们继续努力!

1 An R. A note from the editorial office. Chinese Sci Bull, 2011, 56: 1-2

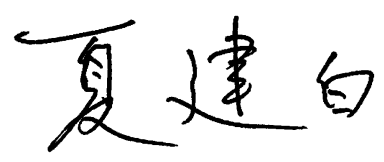

(中国科学院半导体研究所, 北京 100083) 